\title{
A (Im)Pertinência da História ao Aprendizado da Física (um Estudo de Caso)
}

The (IN)convenience of history in learning physics (a case study)

\author{
Penha Maria Cardoso Dias \\ Instituto de Física \\ Instituto Alberto Luiz Coimbra de Pós-Graduação \\ e Pesquisa em Engenharia (COPPE) \\ Universidade Federal do Rio de Janeiro \\ email:penha@if.ufrj.br
}

Recebido em 21/04/2001. Aceito em 20/06/2001

\begin{abstract}
Neste artigo, assumo que a História de uma particular ciência é um legítimo foro de investigação de seus fundamentos. A História revela "o porquê" das categorias conceituais da ciência, clarificando, assim, o significado dos conceitos. Para ilustrar, apresento um estudo de caso: Uma análise conceitual da Teoria do Calor.
\end{abstract}

In this paper I hold the view that the History of a particular science is the most legitimate tool to investigate its foundations. The history of a particular science discloses the "why" of the conceptual categories of that science; hence it clarifies the meanings of its various concepts. To exemplify, I present a "case study", the Theory of Heat, which is a conceptual analysis of Thermodynamics.

\section{Introdução: Meu tipo de história da física}

Para quê serve a História da Física? Ou, mais especificamente, é a História de uma ciência necessária ou, ao menos, útil para a análise de seus fundamentos? Entendo que:

A História é o foro, onde a análise conceitual pode ser feita; ela permite rever conceitos, criticá-los, recupera significados e os entende à luz de novas descobertas. Ela é, pois, o instrumento da formação intelectual $e$ da assimilação de conceitos. Conseqüentemente, a História de uma ciência é essencial à heurística da descoberta científica. Ela é o instrumento de formação de pensadores. Na medida em que critica, ela subverte, mas dentro de métodos e categorias do pensamento: Portanto, a História é o instrumento da formação de uma mente disciplinadamente indisciplinada na crítica dos conceitos cientificos.

Há outros modos de se fazer História da Física. A História de uma ciência permite uma multiplicidade de enfoques, dependendo das perguntas às quais o historiador se dirige: $O$ pano de fundo cultural, social e político ou, no jargão, a Weltanschauung para a leitura dos conceitos e métodos; o contexto filosófico do pensamento científico, isto é, categorias filosóficas ge- rais, que são os pressupostos epistemológicos da possibilidade do pensamento científico, tais como, causalidade, substância, etc, e categorias filosóficas particulares, como o vínculo a doutrinas filosóficas particulares, tais como atomismo, ocasionalismo, etc; a História das instituições científicas; etc. Esses modos não precisam ser estanques e revelam a ciência como atividade cultural da espécie homo sapiens sapiens.

Porém, nem todos os modos de se fazer História servem ao propósito do aprendizado de conceitos ou servem aos fundamentos da ciência. Na próxima seção, exemplifico questões de fundamentos da Física que encontram resposta em sua História. Na outra seção, ilustro esse uso com um exemplo específico: A construção das duas leis da Teoria do Calor; essa construção põe a descoberto seus fundamentos.

\section{PARTE I - Uso da história na clarificação de conceitos}

(I) A Física é não-trivial, em sua essência. Porém, o uso de um conceito, ao longo de muitos anos e, até séculos, tende a trivializar o não trivial; isto é, dificuldades conceituais são banalizadas, conceitos são tratados como "óbvios". Isso deixa a desagradável sensação de que os 
conceitos são "mágicos".

Exemplificando: A Física começa enumerando as três leis da Mecânica. Ora, a Lei da Inércia, a primeira delas, nem sequer é motivo de observação no dia a dia. Que grau de confiabilidade pode-se ter, pois, nessa Lei? O ponto é que a discussão do problema da existência ou não do vácuo e da possibilidade, ainda que meramente racional, do movimento inercial, nos séculos XIII e XIV, mostra os problemas que os conceitos de vácuo e de seu associado, o movimento inercial, pretendem solucionar, mostra os argumentos que convenceram àqueles que fundaram a Física.

É claro que, ao perguntar sobre o "grau de confiabilidade" está colocado todo um problema de Epistemologia. Esse ramo da Filosofia estuda a natureza do conhecimento científico, tenta provar que o conhecimento da natureza é possível e traça os cânones do pensamento científico. Por exemplo, uma ciência tem de ser capaz de predizer o comportamento da Natureza; a condição para isso ser possível é qua a Natureza obedeça a leis; mas, então, qual a origem dessas leis? Não tenho a pretensão de atacar problemas filosóficos controversos e que têm sido discutidos pelos mais brilhantes filósofos. O problema a que me dirijo é bem mais elementar. Assumindo provada a possibilidade da ciência, assumindo que a ciência, de fato, "explica alguma coisa", o problema é o de tornar inteligível as leis da Física, entender seu significado físico e metafísico; é o de tornar "menos mágicos", conceitos tão pouco intuitivos e naturais, como, por exemplo, as Leis de Newton. Afinal, as leis da Física e da Matemática tornaram possível mandar foguetes a Saturno e Júpiter, inventar computadores, as leis da Biologia estão desvendando o código genético, desvendando a "vida", enquanto a Epistemologia ainda tenta provar que tudo isso é possível.

A História da descoberta de um conceito mostra não somente como o conceito foi criado, mas, sobretudo, seu porquê; a História mostra as questões para cujas soluções o conceito foi introduzido, revela o quê o conceito faz na teoria, sua função e seu significado. A História revive os elementos do pensar de uma época, revelando, pois, os ingredientes com que o pensamento poderia ter contado na época em que determinada conquista foi feita. Ela desvenda a lógica da construção conceitual; nesse esforço, ela revela, também, os "buracos lógicos" que o conceito preenche, revivendo o próprio ato intelectual da criação científica.

(II) Algumas questões dos Fundamentos da Física são filosóficas em sua natureza. Essas questões são o próprio estofo da Filosofia da Física e, da mesma forma que, em Filosofia, a perspectiva histórica é parte da metodologia, assim o é aqui. Para citar alguns exemplos:

(1) Por que seria "o Livro da Natureza escrito na linguagem da Matemática"?

(2) As moléculas e átomos obedecem às leis da Mecânica (não importa se Clássica ou Quântica). Como pode, então, o determinismo microscópico ser conciliado com o indeterminismo macroscópico da Segunda Lei da Termodinâmica? A resposta a essa questão gerou ramos da Física (Mecânica Estatística) e ramos da Matemática (Teoria Ergódica, que, por sua vez, gerou a Teoria de Sistemas Dinâmicos, a que alguns dão o nome de Teoria do Caos). Qual a relação entre o conceito de probabilidade e o de indeterminismo? Probabilidade entra na Física por uma questão de ignorância humana quanto à "preparação" do sistema ou é outra coisa? Ou seja, pondo a pergunta em outras palavras, qual o conceito de 'probabilidade' mais apropriado à Mecânica Estatística?

(3) O quê dizer da Mecânica Quântica? Qual o conceito de realidade mais apropriado a ela? Durante décadas essa questão foi tratada em departamentos de Filosofia nos Estados Unidos e Inglaterra (onde alguns departamentos de Filosofia são genuinamente dedicados à Filosofia da Natureza); depois dos experimentos de Abner Shimony e seus associados, para provar as desigualdades de Bell, os departamentos de Física "descobriram" o problema.

(4) Por que o programa mecanicista, fundado nos séculos XVII e XVIII, por René Descartes, Christian Huygens, Isaac Newton e Gottfried Wilhelm Leibniz, de olhar para a Natureza como matéria em movimento "dá conta do mundo", "funciona" tão bem? Será que o mundo (da Física) é só isso, "matéria em movimento"?

(5) A Física nasceu do problema colocado na Antigüidade Helênica de explicar transformações em geral, incluindo o movimento local, isto é, o deslocamento. Ora, colocar o movimento nesse bolo foi essencial. Mais essencial, ainda, foi entender que o movimento poderia ser tratado como uma qualidade como qualquer outra, tal como bondade, cor, etc, portanto a ele se aplicariam as leis medievais para tratar qualidades. Aplicação dessas leis corresponde a tratar o movimento no "espaço" extensão $\times$ intenção ou tempo $\times$ velocidade instantânea. Isso deu origem à Cinemática. Aqui, os pressupostos filosóficos agiram "a favor". Ou será mais que um acaso? Qual o valor epistêmico dessas analogias positivas?

(6) O quê dizer dos princípios de economia, como os Princípios de Maupertuis, a Lei de Fermat, etc? A justificativa deles é metafísica: Existe na Natureza uma tendência a agir "simples e economicamente"; ora, isso funcionava no século XVIII, quando a Natureza espelhava os desígnios do Criador; e hoje, na ciência atéia, qual o significado desses princípios? Por exemplo, eu provei que Leonhard Euler interpretou os princípios de Maupertuis como um processo de conversões instantâneas, sucessivas, de energia potencial em cinética, fundando, assim, a Mecânica Analítica ${ }^{1}$ com isso, o princípio metafísico torna-se físico.

(7) Por falar em energia, qual o sentido físico da necessidade de existência de quantidades conservadas? Sabe-se que as constantes do movimento são geradores 
de transformações canônicas; em particular, a energia "gera" o movimento, no espaço de fase. O próprio "status" ontológico da energia é curioso; ela é matéria, ou, na linguagem aristotélica, substância, isto é, uma das categorias do pensamento. Quantidades conservadas não poderiam, portanto, estar relacionadas à própria possibilidade da Física, serem critérios ontológicos de definição do sistema?

Talvez seja significante, nesse contexto, o fato que a existência de uma única quantidade, a energia, "explica" o equilíbrio termodinâmico, isto é, a distribuição micro-canônica de estados no espaço de fase, como descoberto por Ludwig Boltzmann (neste ponto, está-se retornando a (2), acima).

(8) Por que causas são iguais a seus efeitos? Uma das críticas de Jean Le Rond D'Alembert à equação de Newton, é que ela exige que se iguale a causa, $\vec{F}$, a seu efeito, $m \vec{a}$.

(9) O debate sobre a natureza do espaço e do tempo entre Newton (ou melhor, seu "menino de recados", Samuel Clarke) e Leibniz deu-se em torno do conceito de continuidade, da relatividade do movimento, do princípio da razão suficiente (Deus não precisa ficar continuamente "dando corda" no mundo, como queria Newton, para o mundo funcionar, pois nada acontece sem razão que assim seja). Segundo Leibniz, se o movimento é relativo, então espaço não pode ser absoluto. Porém, deve existir um elemento absoluto, que traga uma acerta "identidade" às coisas; para ele, é a força, aqui entendida não só como a causa da aceleração, mas, também no sentido metafísico de força ativa primitiva ou entelequia e força passiva primitiva ou substância. $\mathrm{O}$ ponto é: Qual a natureza do espaço e do tempo? A Teoria da Relatividade Geral, assim inicialmente denominada por Albert Einstein, deve ser capaz de responder à questão.

(10) Muitas questões acima, tidas como "metafísicas", podem vir a adquirir resposta dentro da Física, perdendo o status de metafísicas. Mas nem todas. Categorias de Substância, Qualidade, Relação e outras são princípios a-priori do pensamento e determinam o tipo de questão que se pode perguntar sobre a Natureza. Segundo Emmanuel Kant, são condições de possibilidade do pensamento científico. Se assim for, então é impossível fazer ciência sem uma dose de princípios metafísicos.

Além disso, se assim for, a verdade das ciências é condicionada à formação das categorias do pensar do homo sapiens sapiens, ao funcionamento do cérebro humano. Não haveria, aqui, um problema "ovo-galinha"? O comportamento neuro-fisiológico do cérebro depende das leis da Física e da Química, por outro lado, essas leis são o produto daquele.

(III) Existe uma relação profunda entre a História da Ciência e a Epistemologia. Segundo E. J. Dijksterhuis, a História é o Laboratório da Epistemologia. ${ }^{2}$ Nesse sentido, ela aponta os ingredientes envolvidos na construção ou descoberta do conceito, revelando o grau de racionalidade do ato da descoberta. Alguns autores (Imre Lakatos) foram além e postularam que só "research programmes" e não teorias isoladas podem ser falsificadas, portanto o valor epistêmico da ciência só pode ser avaliado ao longo de sua História.

\section{PARTE II - Estudo de caso: A teoria do calor}

O exemplo é uma das mais belas páginas do pensamento humano - a descoberta da Segunda Lei da Termodinâmica e de sua misteriosa acompanhante, a entropia.

Algumas perguntas podem surgir ao estudante crítico:

(1) Por que a máquina de Carnot envolve duas temperaturas e não uma? Afinal, o que existe de intuitivo ou, pelo menos, deglutível, no ciclo de Carnot?

(2) O quê significa a segunda lei? O quê é entro$p i a$ ? Ela mede o quê? Seria $\oint \frac{d Q}{T} \geq 0$ inteligível como expressão matemática daquilo que a entropia mede?

A História da Teoria do Calor tem muito a dizer sobre algumas dessas questões. O que apresento, aqui, é uma leitura dos fundamentos da Teoria do Calor, extraídos de sua História. Para os detalhes da História, remeto o leitor a meus artigos mencionados no final do texto, onde vasta bibliografia é citada. Nem é o texto um meio de iniciar o estudo da Termodinâmica; pelo contrário, os fundamentos de uma ciência são para quem já a estudou uma vez, teve dúvidas, colocou questões e gosta de pensar.

\section{A máquina térmica}

A máquina térmica usa calor para gerar movimento, isto é, trabalho mecânico.

Máquina de Watt. Água é aquecida em uma fornalha (fonte quente), formando vapor (substância de trabalho). O vapor entra em um cilindro, previamente aquecido à temperatura do vapor, empurrando um êmbolo e realizando trabalho. Depois que o êmbolo é empurrado um pouco, o suprimento de vapor é cortado e o vapor expande por si só, continuando a empurrar o êmbolo e a realizar trabalho. Quando o êmbolo atinge o final do cilindro, o vapor expande para um cilindro, mantido a uma temperatura, fria, o bastante para condensar o vapor (condensador ou fonte fria); o vapor é, pois, "destruído". Em decorrência, forma-se um vácuo no cilindro principal e o êmbolo pode ser trazido de volta à posição inicial.

\section{Princípio de funcionamento da máquina térmica}

Nicolas Léonard Sadi Carnot descobriu os fundamentos do funcionamento da máquina inventada por 
James Watt, isto é, como e porquê a máquina faz o que faz.

Princípio de Carnot. O funcionamento $d a$ máquina térmica consiste na transferência de calor de uma fonte quente para uma fria e não em um consumo de calor. Como conseqüência, calor é conservado na operação da máquina: o calor retirado da fonte quente é todo ele transferido para a fonte fria.

\section{Fundamentação do princípio de Carnot}

(1) Carnot entendeu que:

(i) A máquina de Watt tem de ser capaz de reiniciar novo ciclo de operações (é claro, ninguém deseja uma máquina que só funcione uma única vez).

(ii) A máquina tem de fazê-lo, sem precisar formar uma nova substância de trabalho. ${ }^{3}$

Ora, para voltar ao começo das operações, é preciso que a substância de trabalho jogue fora o calor que recebeu da fonte quente: A fonte fria existe para receber da substância de trabalho (parte d)o calor recebido da fornalha.

(2) Princípio de Economia. Carnot entendeu que, havendo contato entre dois corpos a temperaturas diferentes, calor é transferido sem que trabalho seja realizado, isto é, trabalho é "deixado de ser realizado", logo é "perdido". Assim, para a máquina "trabalhar bem", isto é, não deixar de realizar todo o trabalho que pode, potencialmente, realizar, deve-se evitar que partes a diferentes temperaturas entrem em contato; isso é um princípio de economia.

(3) O Ciclo econômico. Carnot inventou um ciclo de operações de uma máquina, cuja substância de trabalho é um gás perfeito, capaz de transferir calor da fonte quente para a fria, sem perdas:

(i) Expansão isotérmica: A fonte quente e a substância de trabalho estão em contato, à mesma temperatura, cumprindo a condição de economia. À medida que a substância recebe calor da fonte quente, ela expande, empurrando o êmbolo.

(ii) Expansão adiabática: Calor não é trocado com o exterior. A substância esfria à medida que expande. O processo é interrompido, quando a substância atingir a temperatura da fonte fria.

(iii) Compressão isotérmica: A fonte fria e a substância de trabalho estão em contato, à mesma temperatura, cumprindo a condição de economia. À medida que a substância for comprimida, calor é transferido da substância de trabalho para a fonte fria. Quando a substância atingir "certo volume" (qual?), deve-se interromper essa fase.

(iv) Compressão adiabática: Calor não é trocado com o exterior ou outra qualquer parte e a substância esquenta à medida que for comprimida. O processo é interrompido, quando a substância atingir a temperatura da fonte quente. ${ }^{4}$

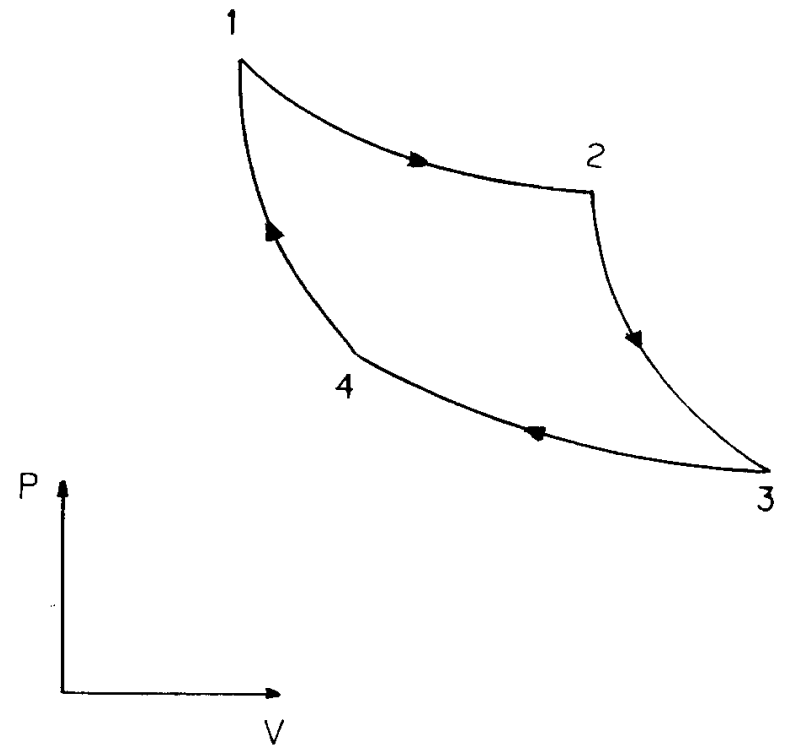

Figura 1. O Ciclo de Carnot. O ciclo de Carnot é desenhado no "espaço" volume $\times$ pressão; como a temperatura é ligada a $V$ e $P$ pelas equações da isoterma(s) e da adiabática(s), segue-se que, dadas as curvas, o ciclo só tem duas variáveis independentes, $P$ e $V$. As curvas 12 e 34 são isotermas, respectivamente, às temperaturas $T_{+}$, quente, e $T_{-}$, fria; as curvas 23 e 41 são adiabáticas.

(4) Carnot raciocina como se calor fosse um fluido muito fino, capaz de penetrar os menores poros da matéria; esse fluido era chamado de calórico. O funcionamento da máquina consiste, pois, na transferência de calórico da fonte quente para a fonte fria. Findo o ciclo completo, a máquina recupera suas condições iniciais. Como posto por Carnot, o Princípio de Carnot é uma condição de recuperabilidade das condições iniciais da máquina; para isso, a substância de trabalho tem de voltar às suas condições originais, livrando-se do calórico recebido. Nesse processo, o calórico é conservado, pois não é utilizado, gasto, "consumido", é só um "meio de transporte".

\section{O teorema de Carnot}

Carnot demonstra um teorema, segundo o qual $a$ eficiência da máquina térmica, funcionando de acordo com o ciclo acima, não depende da substância de trabalho usada, isto é, se um gás perfeito ou outro gás perfeito ou se alguma outra substância.

Para provar o teorema, Carnot supõe duas máquinas, operando entre as duas mesmas temperaturas, $T_{+}$e $T_{-}$, uma operando no ciclo direto e a outra, no ciclo reverso de operações; porém, elas usam diferentes substâncias de trabalho. As máquinas são acopladas, isto é, o trabalho, $W$, obtido na primeira é usado para operar a segunda. Carnot assume que somente uma parte do trabalho, $W^{\prime}\left(W^{\prime}<W\right)$, gerado na primeira precisa ser usado na segunda máquina. ${ }^{5} \mathrm{~A}$ máquina direta traz calor, $Q$, da fonte quente para a fria e a máquina revertida faz o caminho inverso, devolvendo todo o calor, $Q$, à fonte quente. O resultado 
é que a fonte quente e a substância de trabalho recuperam suas condições iniciais. Porém, resulta um trabalho grátis, $W-W^{\prime}$, tirado do nada, pois só se usou parte do trabalho obtido na máquina direta. Ora, é um dos princípios metafísicos da Física (e, talvez, da vida) que se deve pagar por um trabalho realizado. ${ }^{6}$ Carnot conclui que sua hipótese de que só parte do trabalho obtido fosse necessário para operar a máquina revertida era errada: Ambas produzem (e utilizam, quando revertidas) a mesma quantidade de trabalho. Como, por hipótese, as máquinas operam com substâncias diferentes, o resultado é que o trabalho independe da substância de trabalho.

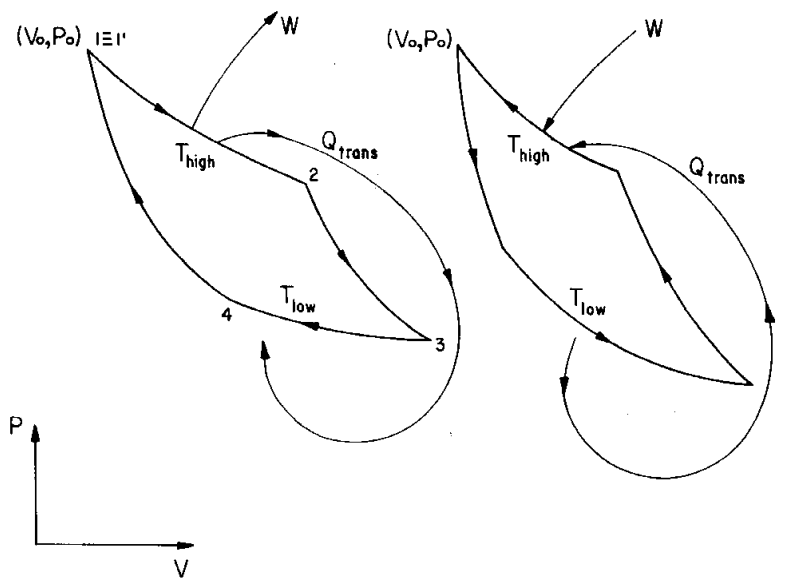

Figura 2. O Teorema de Carnot, como entendido pelo próprio Carnot. A máquina direta retira um calor, $Q$, da fonte quente e, nesse processo, de alguma forma, produz trabalho, $W$; a substância de trabalho livra-se de $Q$, lançando-o na fonte fria. O trabalho $W$ é usado para operar a máquina reversa, cuja operação é devolver $Q$ à fonte quente.

Em outras palavras, a eficiência,

$$
\frac{\text { trabalho }}{\text { calor retirado da fonte quente }}
$$

independe da substância de trabalho. Mas, então, do quê depende? Ora, só pode depender do que for $n u-$ mericamente igual nos dois ciclos, o direto e o reverso. Ora, as variáveis "iguais" são: por hipótese, $Q, T_{+}, T_{-}$ e, pelo teorema, $W$.

\section{O dilema de Thomson}

William Thomson, o futuro Lorde Kelvin, colocou o seguinte dilema:

(i) James Prescott Joule demonstrou, por experimentos, que calor pode ser transformado em trabalho e vice-versa.

(ii) Portanto, se a máquina realiza trabalho, calor não pode ser, todo ele, transportado de uma fonte para a outra. Ele tem de "virar" trabalho, isto é, ser consumido, usado, gasto.

(iii) Logo, ou Carnot está certo e Joule errado; ou Carnot está errado e Joule certo.

\section{Clausius responde a Thomson}

Rudolf Julius Emmanuel Clausius entendeu que não há contradição entre os dois princípios, desde que o Princípio de Carnot sofra pequena modificação:

(1) Clausius aceita os resultados de Joule: Calor é trabalho, logo se trabalho é obtido, calor é consumido.

(2) Clausius corrige Carnot: O calor retirado da fonte quente não pode ser todo ele transferido, mas parte é consumida. Ele distingue, pois, duas operações nas máquinas térmicas:

(i) Transformação de calor em trabalho ou consumo de calor: Parte do calor recebido da fonte quente é transformada em trabalho, durante a expansão isotérmica.

(ii) Transporte de calor da fonte quente para a fonte fria: A parte restante do calor, que foi recebido da fonte quente, é transferida para a fonte fria, durante a compressão isotérmica.

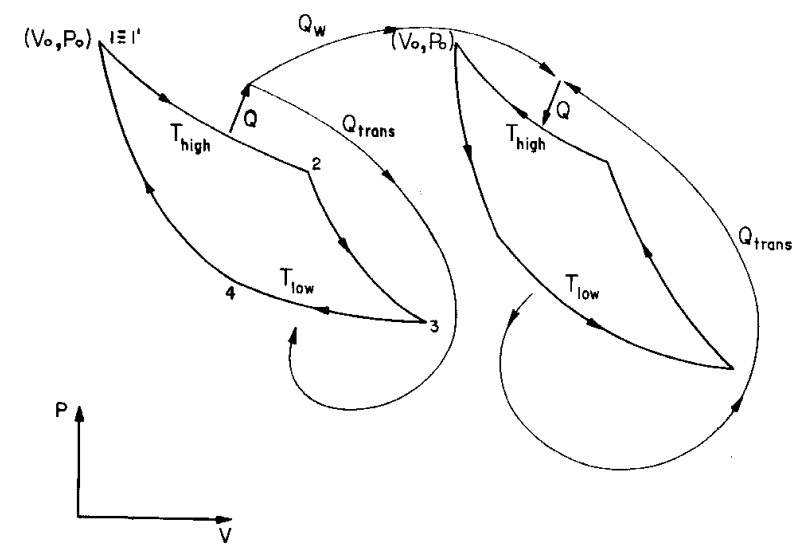

Figura 3. O Teorema de Carnot, como entendido por Clausius. A máquina direta retira um calor, $Q$, da fonte quente: Parte desse calor é transformada em trabalho: $W$ é, pois, o calor consumido; o restante, $Q-W$, é transportado para a fonte fria. O trabalho $W$ é usado para operar a máquina reversa, cuja operação é devolver $Q-W$ à fonte quente.

(3) Teorema de Carnot. A máquina direta retira calor, $Q$, da fonte quente. Parte desse calor é consumido, isto é, transformado em trabalho, $W$. O calor restante, $Q-W$, é transportado para a fonte fria. O mesmo $W$ é usado para operar a máquina reversa; porém, assume-se que essa transporte um calor $Q^{\prime}$ da fonte fria para a fonte quente. Ora, se for $Q^{\prime}>Q$, o resultado final do acoplamento das máquinas é uma quantidade de calor, $Q^{\prime}-Q$, transportada da fonte fria para a fonte quente sem nenhum trabalho gasto para isso, pois todo o $W$ foi usado para operar a máquina reversa; para proibir isso, Clausius "tira do bolso" o seguinte princípio: o fluxo natural do calor é dos corpos quentes para os frios. Logo, $Q^{\prime}=Q .^{7}$ 


\section{O princípio de Joule}

O Princípio de Joule significa que calor e trabalho são grandezas homogêneas; logo:

$$
\frac{\text { trabalho }}{\text { calor consumido }}=1 \text {. }
$$

Como as quantidades são medidas em unidades diferentes, em vez de 1 aparece um outro valor para a constante, $A$; é circunstancial que $A=4,18 \frac{\text { joule }}{\text { caloria }}$, pois esses valor resulta do fato de que, por alguma razão, "alguém" usou caloria para medir calor e joule para medir trabalho.

Depois de muita conta (apêndice), Clausius reescreve a expressão acima como:

$$
d U=-p d V+d Q .
$$

As contas não são "iluminantes", exceto pelo seguinte: Segue-se, no fluir dos cálculos, que $d U$ é uma diferencial total, isto é, $U$ é integrável, enquanto $Q$ e $W$ não são integráveis, logo $d Q$ e $d W$ não são diferenciais totais. Portanto, o Princípio de Joule é uma lei de conservação: Ao término de um ciclo, a substância de trabalho volta às suas condições iniciais. A lei de Joule significa: o conteúdo de calor da substância da trabalho, $U$, é recuperado, após um ciclo completo da máquina direta.

\section{Generalização do teorema de Carnot}

(1) Clausius entendeu que a demonstração do teorema, envolvendo, apenas, duas temperaturas, é muito simples, pois consumo se dá em uma das duas temperaturas entre as quais se efetua a transferência, porém pode ser que as relações entre as quantidades de calor envolvidas em uma e outra operação varie diferentemente com a temperatura. Assim, Clausius inventou um ciclo mais complicado, com três temperaturas:
Todo o calor absorvido na fonte com a maior temperatura $\left(T_{+}\right)$é transformado em trabalho (consumo); todo o calor absorvido na fonte com a temperatura intermediária $\left(T_{i}\right)$ é transportado para a fonte fria (transporte), $T_{-}$.

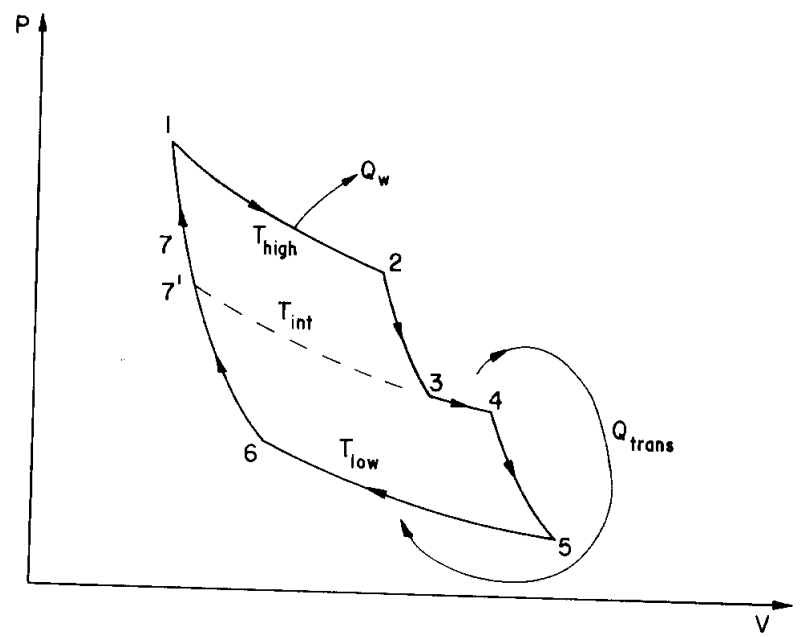

Figura 4. O Ciclo de Três Temperaturas. O calor retirado da fonte quente, $T_{+}$, é todo ele transformado em trabalho. O calor retirado da fonte intermediária é todo ele transferido à fonte fria, $T_{-}$.

(2) Clausius segue a inspiração original de Carnot de que o princípio de funcionamento da máquina térmica expressa uma lei de conservação. Mas de quê? Para responder, ele inventa outra demonstração do Teorema de Carnot.

Clausius raciocina que, após um ciclo, as duas operações se cancelam, pois há uma volta às condições iniciais. Ele, então, atribui valores de eqüivalência às duas operações:

\section{OPERAÇÃO}

transformação de calor em trabalho na temperatura $T_{+}$ transformação de trabalho em calor na temperatura $T_{+}$ transporte de calor na temperatura $T_{i}$ em calor na temperatura $T_{-}$ transporte de calor na temperatura $T_{-}$em calor na temperatura $T_{i}$

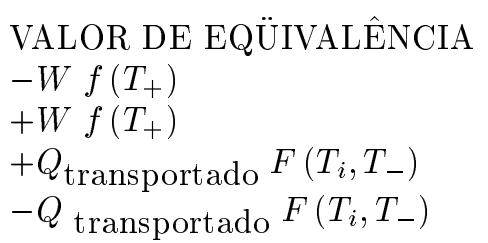

A lei de conservação introduzida por Clausius, após um ciclo, é:

$$
-W f\left(T_{+}\right)+Q \text { transportado } F\left(T_{i}, T_{-}\right)=0 .
$$

Aplicando a expressão a uma máquina revertida similar, mas operando com a temperatura alta com valor $T_{i}<T_{+}^{\prime}<T_{+}$e capaz de transportar a mesma quanti- dade de calor $Q$ transportado:

$$
+W^{\prime} f\left(T_{+}^{\prime}\right)-Q_{\text {transportado }} F\left(T_{i}, T_{-}\right)=0 .
$$

Somando:

$$
-W f\left(T_{+}\right)+W^{\prime} f\left(T_{+}^{\prime}\right)=0 .
$$


Significa que a operação das máquinas, agindo acopladamente, é a transformação de uma quantidade de $c a$ lor, $W$, em trabalho na temperatura $T_{+}$e de uma quantidade, $W^{\prime}$, de trabalho em calor em $T_{+}^{\prime}$. Ora, se a fonte $T_{+}^{\prime}$, agindo como fria, recebe um calor $W^{\prime}$ e a fonte $T_{+}$, agindo como quente, cede $W$, significa que o acoplamento é equivalente a uma máquina operando entre $T_{+}$ e $T_{+}^{\prime}$, que realiza trabalho $W-W^{\prime}$ e transporta $W^{\prime}$; logo:

$$
-\left(W-W^{\prime}\right) f\left(T_{+}\right)+W^{\prime} F\left(T_{+}, T_{+}^{\prime}\right)=0 .
$$

Somando e subtraindo $W^{\prime} f\left(T_{+}\right)$a (3) e agrupando termos:

$$
-\left(W-W^{\prime}\right) f\left(T_{+}\right)+W^{\prime}\left[f\left(T_{+}^{\prime}\right)-f\left(T_{+}\right)\right]=0
$$

$\operatorname{Mas}\left(3^{\prime}\right)$ e

(4) descrevem a mesma máquina, logo:

$$
F\left(T_{+}, T_{+}^{\prime}\right)=f\left(T_{+}^{\prime}\right)-f\left(T_{+}\right) .
$$

(3) A demonstração acima envolve o uso da máquina revertida. Logo, a seguinte condição de conservação vale para um ciclo completo, reversível:

$$
-W f\left(T_{+}\right)+Q \text { transportado }\left[f\left(T_{-}\right)-f\left(T_{+}\right)\right]=0 .
$$

Mudando a notação e denotando por $T$ não mais a temperatura, mas uma função só da temperatura, definida por $f \equiv \frac{1}{T}$, o Teorema de Carnot tem a seguinte expressão: ${ }^{8}$

$$
\text { lei de conservação do ciclo reversível: } \sum_{j=1}^{j=3} \frac{Q_{j}}{T_{j}}=0 \text {. }
$$

"Claro" que a fórmula acima pode ser generalizada: $\oint \frac{d Q}{T}=0$. O Teorema de Carnot produz, pois, uma diferencial total, $d S \equiv \frac{d Q}{T}$. O Princípio de Carnot é, de fato, uma lei de conservação: Ao término de um ciclo da máquina revertida, a fonte quente volta às suas condições iniciais, recuperando seu conteúdo de calor. Para isso, após um ciclo da máquina direta, a quantidade $S$ tem de recuperar seu valor original. (4) Mas

Clausius já parte de uma expressão suspeita para o $v a-$ lor de eqüivalência. Trapaça? É claro: Ele já devia ter resolvido milhões de ciclos para o gás perfeito e a expressão $\sum_{j=1}^{j=3} \frac{Q_{j}}{T_{j}}=0$, com toda certeza, sempre aparecia. Entretanto, existe uma razão para essa expressão.

O resultado do Teorema de Carnot, já modificado por Clausius, é que dois gases perfeitos, diferentes, trabalhando entre as mesmas duas temperaturas, que produzem o mesmo trabalho, transferem para a fonte fria a mesma quantidade de calor.
Os gases, sendo diferentes, as equações de estado (isto é, a lei do gás perfeito) dos dois gases têm diferentes constantes:

$P V=\frac{\text { massa }}{\text { peso molecular }} R T=$ (número de moles) $R T$; portanto dois gases têm curvas idênticas somente quando têm o mesmo número de moles.

$W$ é não integrável, logo depende das trajetórias que compõem o ciclo; como as equações diferem, para que $W$ tenha o mesmo valor nos ciclos, as figuras dos dois ciclos não se podem superpor: Mesmo que as temperaturas sejam iguais e os processos partam das mesmas condições iniciais, as posições das isotermas e das adiabáticas dos dois ciclos no "espaço" $V \times P$ não precisam coincidir (isto é, os valores de $V$ e $P$ onde os processos começam e terminam não precisam coincidir); nem precisam os traçados dos dois ciclos coincidir, isto é, as curvaturas de cada uma das curvas que compõem o ciclo podem ser respectivamente diferentes nos ciclos de um gás e do outro.

As conseqüências são:

(i) Qualquer quantidade que tenha o mesmo valor nos dois ciclos, portanto, independentemente das posições e da forma dos ciclos no espaço $V \times P$ só pode depender de $V$ e $P$ através de $Q, T_{+}$e $T_{-}$. Carnot fez $d W=d Q f(T)$; Clausius fez $d S=d Q f(T)$.

(ii) Carnot está errado, porque $W$ depende do ciclo e, de fato, a condição de que seja o mesmo nos dois ciclos determina (junto, é claro, com as equações das curvas) o traçado do ciclo.

(iii) O Teorema de Carnot, como generalizado por Clausius, é mais bem entendido assim: Dado que o Princípio de Carnot é uma condição de conservação no ciclo reversível e dado que a quantidade conservada é função de $Q, T_{+}$e $T_{-}$, somente, Clausius supôs que ela tivesse a forma $Q f(T)$; então, ele prova que a equação

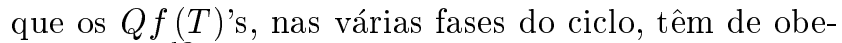
decer é $\oint \frac{d Q}{T}=0 .{ }^{9}$

\section{Conclusão}

Em que a explicação das duas leis da Termodinâmica apresentada acima é melhor que outras? Minha defesa é que o uso da História da Física realça os problemas e questões que forçaram Carnot e Clausius a formularem a Termodinâmica. E, por isso, quero crer, torna as leis menos "mágicas". A História coloca em evidência a "operação mental" que leva do "Laboratório da Natureza" à lei geral. Há argumento para se entender "a força das evidências" mais forte do que o quê aconteceu na ordem fatual da vida? 


\section{Apêndice:}

O princípio de Joule

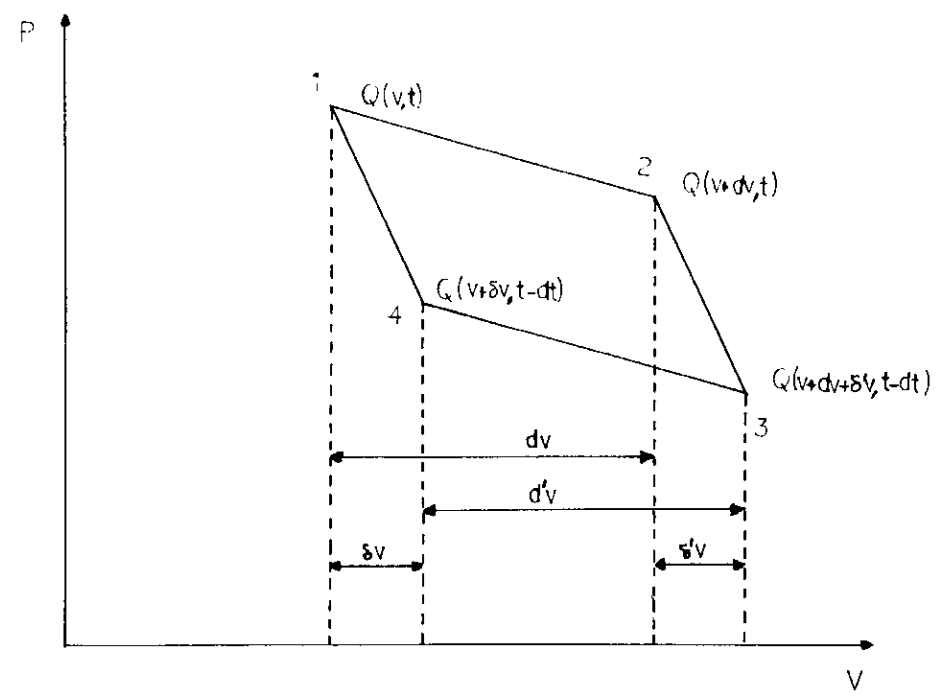

Figura 5. Ciclo de Carnot infinitesimal. O ciclo pode ser aproximado por um paralelogramo. Os acréscimos de volume nos pontos 1, 2, 3 e 4 são mostrados.

calor em 1:

calor em 2:

calor em 4:

calor em 3:

relação entre os acréscimos de volume:

$$
\begin{aligned}
& Q(V, T) \\
& Q(V+d V, T) \\
& Q(V+\delta V, T-d T) \\
& Q\left(V+d^{\prime} V+\delta V, T-d T\right)=Q\left(V+d V+\delta^{\prime} V, T-d T\right)
\end{aligned}
$$$$
d V+\delta^{\prime} V=\delta V+d^{\prime} V
$$

calor consumido:

(1)-(2)

$$
\frac{\partial Q(V, T)}{\partial V} d V-\left[\frac{\partial Q(V, T)}{\partial V}+\frac{\partial^{2} Q(V, T)}{\partial V^{2}} \delta V-\frac{\partial^{2} Q(V, T)}{\partial V \partial T} d T\right] d^{\prime} V
$$

processo adiabático:

$$
Q(V+\delta V, T-d T)=Q(V, T)
$$$$
\frac{\partial Q(V, T)}{\partial V} \delta V=\frac{\partial Q(V, T)}{\partial T} d T
$$

processo adiabático:

$$
\begin{aligned}
& Q(V+d V, T)=Q\left(V+d V+\delta^{\prime} V, T-d T\right) \\
& \left(\frac{\partial Q(V, T)}{\partial V}+\frac{\partial^{2} Q(V, T)}{\partial V^{2}} d V\right) \delta^{\prime} V=\left(\frac{\partial Q(V, T)}{\partial T}+\frac{\partial^{2} Q(V, T)}{\partial V \partial T} d V\right) d T
\end{aligned}
$$

As expressões (A), (B) e (C) são vínculos e são usadas para calcular $\delta V, \delta^{\prime} V$ e $d^{\prime} V$ em função de $d V$ e $d T$. Para facilitar, derivadas parciais primeiras serão indicadas por índices $T$ e $V$ e derivadas parciais segundas, por $V V, T T$, $V T$ e $T V$. O resultado é:

$$
\begin{array}{ll}
\delta V= & \frac{Q_{T}}{Q_{V}} d T \\
\delta^{\prime} V= & \frac{d T}{Q_{V}}\left(Q_{T}-\frac{Q_{V V}}{Q_{V}} Q_{T} d V+Q_{T V} d V\right) \\
d^{\prime} V= & d V+\left(-\frac{Q_{V V} Q_{T}}{Q_{V}^{2}}+\frac{Q_{T V}}{Q_{V}}\right) d V d T
\end{array}
$$


Substituindo esses valores em (3):

$$
\text { calor consumido: } \quad\left(\frac{\partial^{2} Q(V, T)}{\partial T \partial V}-\frac{\partial^{2} Q(V, T)}{\partial V \partial T}\right) d T d V .
$$

Para escrever a expressão do Princípio de Joule, que é o objetivo dessa conta, a Lei dos Gases Perfeitos é necessária:

Então:

$$
\text { lei dos gases perfeitos, } 1 \text { mol: } \quad P V=R T, \quad P=R \frac{T}{V}, \quad \frac{\partial P}{\partial T}=\frac{R}{V}
$$

$$
\text { princípio de Joule: } \frac{\left(\frac{\partial^{2} Q(V, T)}{\partial T \partial V}-\frac{\partial^{2} Q(V, T)}{\partial V \partial T}\right) d V d T}{\frac{R}{V} d V d T}=A \text {. }
$$

Isso pode ser escrito:

$$
\begin{gathered}
Q_{T V}-Q_{V T}=\frac{A R}{V} \equiv A \frac{\partial P}{\partial T} \\
\frac{\partial}{\partial T}\left(\frac{\partial Q}{\partial V}-A P\right)-\frac{\partial}{\partial V}\left(\frac{\partial Q}{\partial T}\right)=0
\end{gathered}
$$

Em outras palavras, $d Q$ não é uma diferencial total, mas existe uma $d U$ que é diferencial total e tal que:

Logo:

$$
\begin{gathered}
\frac{\partial U}{\partial V}=\frac{\partial Q}{\partial V}-A P \\
\frac{\partial U}{\partial T}=\frac{\partial Q}{\partial T} .
\end{gathered}
$$

$$
d U \equiv \frac{\partial U}{\partial V} d V+\frac{\partial U}{\partial T} d T=-A P d V+\left(\frac{\partial Q}{\partial V} d V+\frac{\partial Q}{\partial T} d T\right)=-A P d V+d Q
$$

\section{Notas}

1. "Euler's "Harmony" Between the Principles of "Rest" and "Least Action" (The Conceptual Making of Analytical Mechanics)", Archive for History of Exact Sciences 54 (1999), 67-86.

2. Dijksterhuis escreveu uma das melhores histórias da Mecânica: The Mechanization of the World Picture; em Inglês, Oxford University Press, 1961; Princeton University Press, 1986.

3. Ou seja, máquinas a vapor não são boas, pois o vapor é sempre destruído e calor adicional é gasto para formar um novo vapor. Assim, Carnot supôs uma outra substância para a máquina ideal; ele pensou em $a r$, mas é melhor pensar em um gás perfeito.

4. A equação da isoterma é facilmente obtida:

Lei dos Gases Perfeitos: $P V=R T=$ constante .

Carnot não conhecia a equação da adiabática, que foi achada por Poisson, por volta de 1824. Ela é obtida resolvendo o sistema de equações:

$$
\text { equação constitutiva: } \quad d U=C_{\mathrm{v}} d T
$$

Lei de Joule: $d U \equiv C_{\mathrm{V}} d T=-P d V$

Lei dos Gases Perfeitos: $P V=R T$.

As equações são:

$$
\begin{aligned}
& \text { isoterma: } \quad P V=\text { constante } \\
& \text { adiabática: } \quad P V^{\gamma}=\text { constante }=T V^{\gamma-1} \quad \gamma=\frac{C \mathrm{p}}{C \mathrm{v}}=\frac{C_{\mathrm{v}}+R}{C_{\mathrm{V}}}=1+\frac{R}{C^{\mathrm{V}}} \text {. }
\end{aligned}
$$

A função dos processos adiabáticos é transportar calor de uma fonte à outra, sem perdas; eles fornecem equações de vínculo:

$$
\begin{aligned}
T_{+} V_{2}^{\gamma-1} & =T_{-} V_{3}^{\gamma-1} \\
T_{+} V_{1}^{\gamma-1} & =T_{-} V_{4}^{\gamma-1} \\
\frac{V_{2}}{V_{1}} & =\frac{V_{3}}{V_{4}} .
\end{aligned}
$$


Os processos isotermos têm função dinâmica, pois produzem trabalho às custas de calor ou vice-versa:

$$
\begin{aligned}
& \text { calor retirado da fonte quente: } \quad Q=T_{+} \ln \frac{V_{2}}{V_{1}} ; \\
& \text { calor transferido para a fonte fria: } q=T_{-} \ln \frac{V_{3}}{V_{4}}=T_{-} \ln \frac{V_{2}}{V_{1}} ; \\
& \text { trabalho: } \quad W=Q-q=\left(T_{+}-T_{-}\right) \ln \frac{V_{2}}{V_{1}}
\end{aligned}
$$

5. Se a máquina direta produzir menos trabalho que a reversa, é só inverter o funcionamento das máquinas para que o argumento da prova possa ser aplicado. De forma que a hipótese de Carnot não é restritiva.

6. No caso da máquina a vapor, o preço é pago em "moeda" de combustível queimado para formar vapor e para aquecer a fonte quente.

7. Se for $Q^{\prime}<Q$, é só inverter o funcionamento das máquinas para que o argumento da prova possa ser aplicado. De forma que a hipótese não é restritiva.

8. Clausius nunca provou que a função $T$ é a própria temperatura; ele só o mostra para o gás perfeito. Posteriormente, em sua axiomática da Termodinâmica (1865), ele postula que $T$ é a temperatura e muda o nome valor de eqüivalência da transformação para entropia, uma palavra que ele cunhou para lembrar transformação (tropé, em grego) e energia.

9. No caso de três temperaturas, a eficiência depende, também, de razões dos volumes: As fontes quente e intermediária fornecem calor $Q_{+}$e $Q_{i}$, respectivamente, então:

$$
\begin{gathered}
\text { eficiência }=\frac{W}{Q_{+}+Q_{i}}= \\
=\frac{-\left(T_{+}-T_{i}\right) \ln \frac{V_{4}}{V_{3}}+\left(T_{+}-T_{-}\right) \ln \frac{V_{5}}{V_{6}}}{-\left(T_{+}-T_{i}\right) \ln \frac{V_{4}}{V_{3}}+T_{+} \ln \frac{V_{5}}{V_{6}}} .
\end{gathered}
$$

No caso tratado por Clausius, em que $Q_{+}=W$, segue-se que $\frac{\frac{V_{4}}{V_{3}}}{\frac{V_{5}}{V_{6}}}=\frac{T_{-}}{T_{i}}$ e, então, a eficiência só depende das temperaturas.

Pelo teorema, $Q$ e $W$ são iguais para as máquinas construídas com diferentes substâncias de trabalho, logo a eficiência é a mesma. Entretanto, volumes podem aparecer na expressão da eficiência, como acima. A condição para que o teorema seja válido é que as razões $\frac{V_{4}}{V_{3}}$ e $\frac{V_{5}}{V_{6}}$ sejam, respectivamente, iguais nas duas máquinas, mas não necessariamente os valores $V_{3}, V_{4}$, $V_{5}$ e $V_{6}$ tomados separadamente.

No caso de duas temperaturas, a situação é mais simples. O gráfico de Carnot, para diferenças infini- tesimais de pressão e de volume pode ser reduzido a um retângulo, $d V d P$; logo a expansão de volume na isoterma quente é igual à compressão de volume na isoterma fria, logo, no ciclo infinitesimal, $V_{1} \equiv V_{4}$ e $V_{2} \equiv V_{3}$; como o ciclo finito pode ser entendido como composto de ciclos infinitesimais, o mesmo vale para o ciclo total, finito.

\section{Agradecimentos}

Agradeço à Professora Teresa Stuchi, colega e amiga, pelas muitas discussões e sugestões, que, certamente, melhoraram meu artigo.

Este trabalho contou com suporte financeiro da Fundação Universitária José Bonifácio (FUJB) ao Departamento de Física Matemática do Instituto de Física da UFRJ.

\section{Leitura Suplementar}

Essa leitura da Termodinâmica é defendida nos meus artigos seguintes, onde o leitor poderá encontrar, também, ampla bibliografia da História da Termodinâmica:

- Sadi Carnot: Histórias e Pré-Histórias, Revista da USP, 7 (1990), 61-78.

- A Path from Watt's Engine to the Principle of Heat Transfer, in: Dag Prawitz e Dag Westerstähl (editores), Papers in Logic, Methodology and Philosophy of Science, Kluwer Academic Publishers, Dordrecht, 1994, 425-437.

- The Conceptual Import of Carnot's Theorem to the Discovery of the Entropy, junto com Simone Pinheiro Pinto e Deisemar Hollanda Cassiano, Archive for History of Exact Sciences, 49 (1995), 135-161.

- Sadi Carnot: O Prometeu Moderno, in: Ildeu de Castro Moreira (editor), Coleção Clássicos da Ciência, prefácio ao vol.1, "Reflexões sobre a Potência Motriz do Fogo, de Sadi Carnot", editora da UFRJ, a sair. 